\title{
Nasolabial Flap Tunneled Under Mandible (NLFTUM) - An Alternative to Free Flap, in T3 Tongue Reconstruction
}

\author{
Dr. Jeyashanth Riju \\ MBBS, MS, FHNSO \\ Fellow in Head and Neck Surgical Oncology, Regional Cancer Centre, Trivandrum, Kerala, India \\ Email id-jjriju@yahoo.co.in \\ https://orcid.org/0000-0003-4750-8111
}

Dr. Shaji Thomas

MBBS, MS, MCH

Head of Department, Surgical Oncology, Regional Cancer Centre, Trivandrum

Emailid-shajircc@gmail.com

Dr. Elizabeth Mathew

Iype MBBS, DLO, DNB, PhD.

Addition Professor, Department of Head and Neck Surgical Oncology, Regional Cancer Centre, Trivandrum, Kerala.

Email id-elizabethrcc@gmail.com

\section{Dr. Nebu Abraham George}

MS (Gen Surgery), DNB (Gen Surgery), MRCS(Ed), DNB (Surg Oncology)

Associate Professor, Department of Surgical Oncology, Regional Cancer Centre, Trivandrum.

Email id-georgeabe @ gmail.com

\begin{abstract}
Introduction: Nasolabial flap tunneled under mandible (NLFTUM) is a good option for reconstruction of any T3 lesion in the oral cavity. It is oncologically safe and gives a better functional outcome compared to other locoregional flaps. When compared to free flap it is a cost effective and time saving procedure. Methods: We present a series of our results wherein NLFTUM was used in 9 patients who presented with biopsy proven carcinoma tongue, clinically T3 lesion which was away from the mandible. Wide excision of lesion was performed with neck dissection and NLFTUM reconstruction was used in all patients, preserving mandible. All these surgeries were performed in 2017 in a 5 months window period. A total of 9 flaps were harvested. Adjuvant radiotherapy was given when indicated. Results: Reconstruction was done in 9 patients in whom 7 were men and 2 women. Mean size of the surgical specimen for which reconstruction done was $5.3+/-0.6 \mathrm{~cm}$. $89 \%$ cases had defect which reached posterior 1/3rd tongue. Reconstruction was successful in $89 \%$ of the cases. Total flap necrosis occurred in 1 patient, 2 patient had minimal necrosis in the distal end of the flap, all were managed conservatively. Oral function and swallowing were satisfactory in all these patients. Cosmetic result was comparable to the normal nasolabial flap. There was no major complication associated with the procedure, none needed any major intervention. Conclusion: NLFTUM is reliable for reconstruction of lesion with defect which is as big as $6 \mathrm{~cm}$ in oral cavity, especially for tongue defects, even if it extends to posterior $1 / 3 \mathrm{rd}$. We have used this in tongue defect because of its excellent functional outcome and there is no risk of added complications.
\end{abstract}

Keywords: Nasolabial flap, Oral cancer, Tongue cancer, Reconstruction, Free flap

\section{Introduction}

Tongue carcinoma accounts one of the major oral malignancies in India. ${ }^{[1]}$ Early detection and management play a major role in its management. Most of our patient presents at a late stage. Surgery plays a prime role in its management, while reconstruction decides the quality of life of the patient following surgery.
When major resection of tongue malignancy is done, patient is left with a defect that necessitates a flap reconstruction. Most higher centre prefer free flap. But in centres wherein free flap is not feasible or in high volume centres graft, locoregional flaps plays a major role.

Routinely nasolabial flap was used for tongue defect reconstruction in most centres. But when we are left with a larger defect or a 


\section{International Journal of Innovative Research in Medical Science (IJIRMS) Volume 03 Issue 12 Dec 2018, ISSN: 2455-8737, Imp. Factor - 4.102 \\ Available online at $-\underline{w w w . i j i r m s . i n}$}

posterior tongue defect reconstruction become an additional challenge, especially when the mandible is free. Free flaps remain ideal for such reconstructions, but it needs special expertise, extra operative and anesthesia time, and additional financial expenditure. Despite the fact it has an excellent functional and esthetic outcome.

Costs must be weighed against the benefits to the patient in Indian scenario and in high volume centres, time is an important factor. So modification over the traditional surgeries must be considered with satisfactory functional and cosmetic outcome.

In this case series, we have analysed the modification of island nasolabial flap i.e, nasolabial flap tunneled under mandible(NLFTUM) in the reconstruction of tongue defects, which can be used in defect upto $6 \mathrm{~cm}$ and its outcome.

\section{Patient and Methods}

We retrospectively analysed NLFTUM in 9 patients who presented with biopsy proven carcinoma tongue lesion which was more than $4 \mathrm{~cm}$ and lesion was away from the mandible. Wide excision of the lesion was performed with frozen control with neck dissection NLFTUM was used in all patients, preserving mandible. All these surgeries were performed in 2017 in a 5 months window period. A total of 9 flaps were harvested. Patients characteristics, type of defect reconstructed, flap viability, postoperative complications related to the procedure and functional result achieved with reconstruction including mobility, articulation and swallowing were analysed.

Mean age of patients was 56.9 years $+/-13.54$ (range 38 years to 79 years). Reconstruction was done in $7(77.8 \%)$ men and $2(22.2 \%)$ women. Among 9 NLFTUM flaps harvested 4 was harvested from right $(44.4 \%)$ and 5 from left side (55.6\%). Extra habits in the form of smoking, chronic alcohol intake or pan chewing were noted in 8 patients $(88.8 \%)$. All patients belonged clinically to T3 disease of tongue (fig1) with no ankyloglossia. 2 patients $(22.2 \%)$ received neoadjuvant chemotherapy before the procedure. 7 patients (77.8\%) underwent adjuvant radiotherapy.

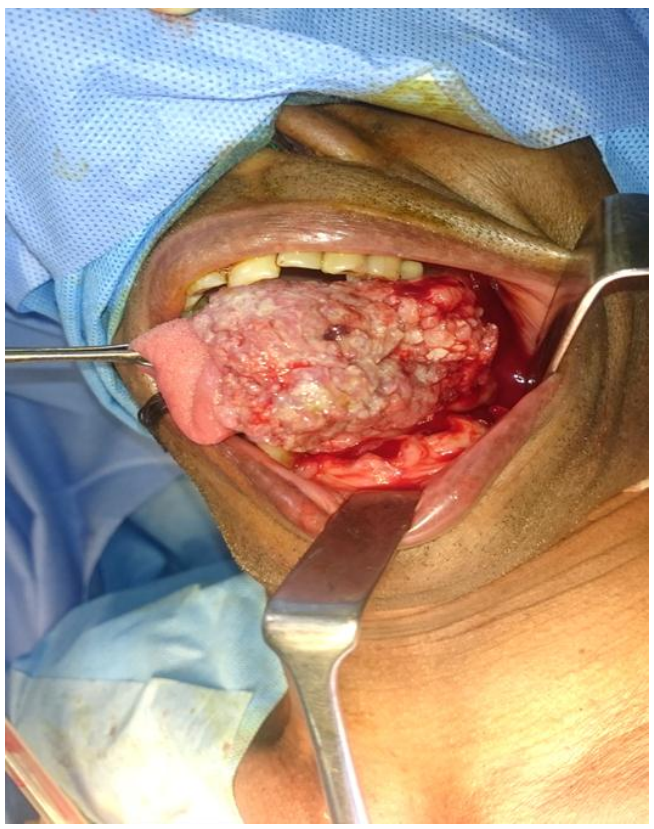

Fig 1: T3 Tongue defect

\section{Surgical Technique}

This Flap is similar to that of the conventional nasolabial island flap with certain modifications. The flap should be harvested with facial artery and facial vein to its maximum extent without compromise to level Ib nodal dissection following which flap is tunneled under the mandible. This flap can be easily harvested under doppler guidance. We have done this flap in 9 consecutive patients without using doppler and method of flap harvest is explained below.

Before harvesting the flap it is worthwhile to remember few important points. Facial vein has a linear course in face. Facial artery has a tortuous course in face and it is around $1.2 \mathrm{~cm}$ lateral to oral commissure. Facial artery is anterior to the facial vein and both diverge during its course. Facial artery and facial vein variations should be carefully looked into. Absence of facial artery is noted in few studies, so it is ideal to do level $\mathrm{Ib}$ clearance and identification of vessels before proceeding to flap harvest. ${ }^{[2]}$ Significant pathological node in level Ib should preclude this flap.

An incision is placed as in nasolabial island flap. Incision is deepened superiorly and facial vein can be easily identified and ligated. Facial vein has a linear course in face. Lateral incision of flap is deepened and dissection is carried out lateral to facial vein in superior to inferior direction, with a minimal cuff of soft tissue and muscle. Now the flap is raised, partly, in plane below the facial vein. Parotid duct can be noted at the end of this dissection and should be preserved. Medial incision of the flap is deepened, deeper tissue is carefully dissected to find the facial artery. Dissection is carried out medial to facial artery and it is ligated as high as possible, with respect to flap, all medial tributaries of facial artery are ligated or clipped, care should be given not to open into the buccal mucosa. Nasolabial flap island can be completely raised now. Facial artery and vein can be skeletonized now, care should be given to preserve marginal mandibular nerve. (Fig 2)

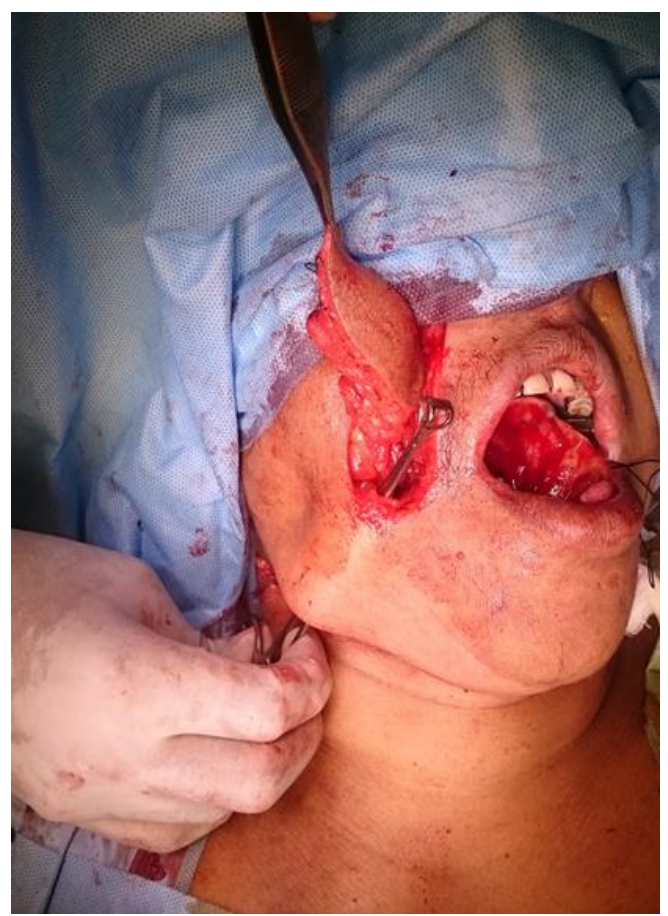

Fig 2: Nasolabial flap harvested and ready to be tunneled to neck 
International Journal of Innovative Research in Medical Science (IJIRMS)

Volume 03 Issue 12 Dec 2018, ISSN: 2455-8737, Imp. Factor - 4.102

Available online at $-\underline{w w w . i j i r m s . i n}$

Complete flap can be tunneled under the skin and got to neck. (Fig $3,4)$ Viability of flap is checked. The flap is now tunneled under the mandible and got out through the tongue defect (Fig 5). Flap to tongue suturing is done with absorbable suture (Fig 6,7,8).

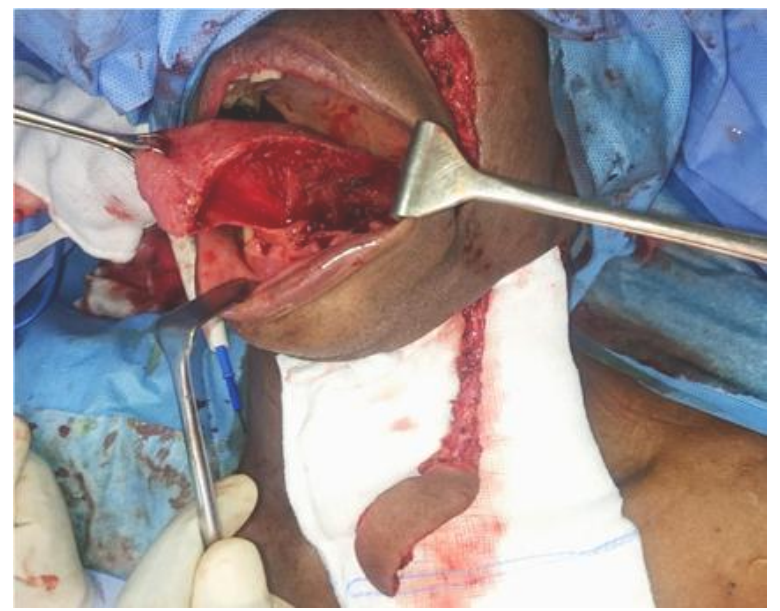

Fig 3: Tongue defect wide excised, Nasolabial flap harvested and tunneled to neck site.

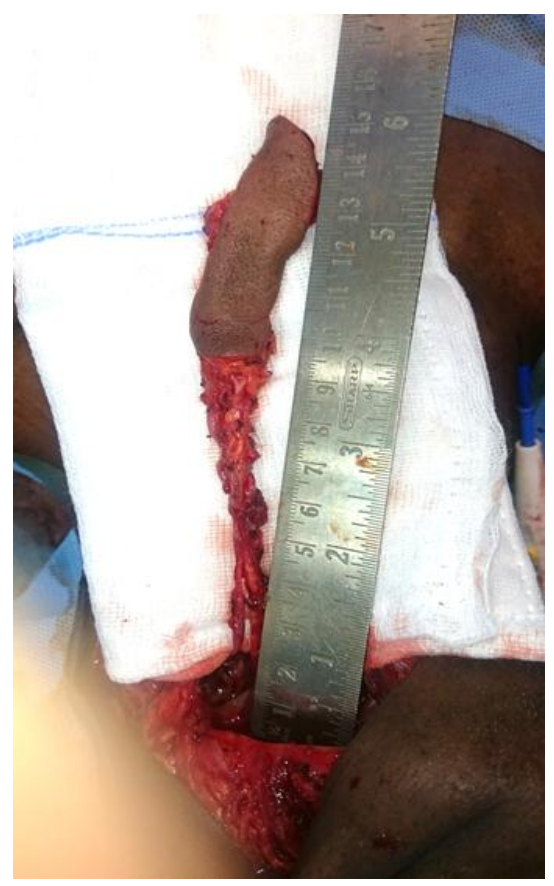

Fig 4: Pedicle length

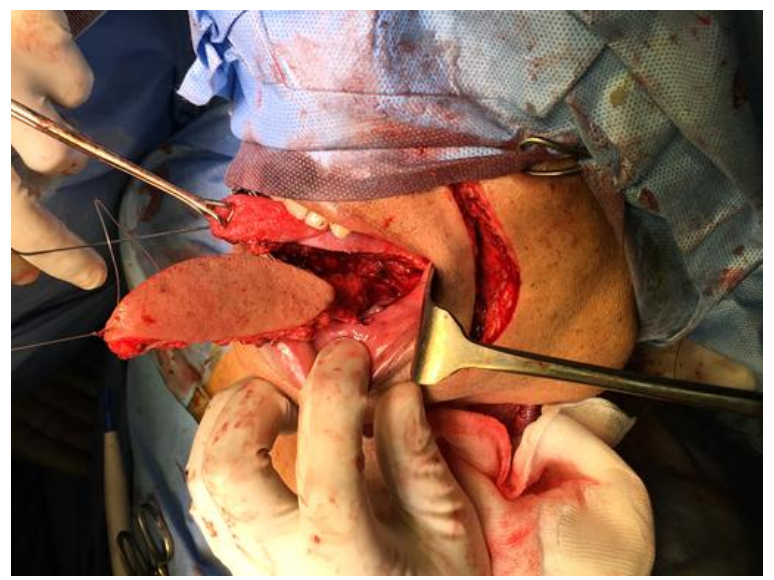

Fig 5: Flap tunneled under mandible and got through tongue defect.

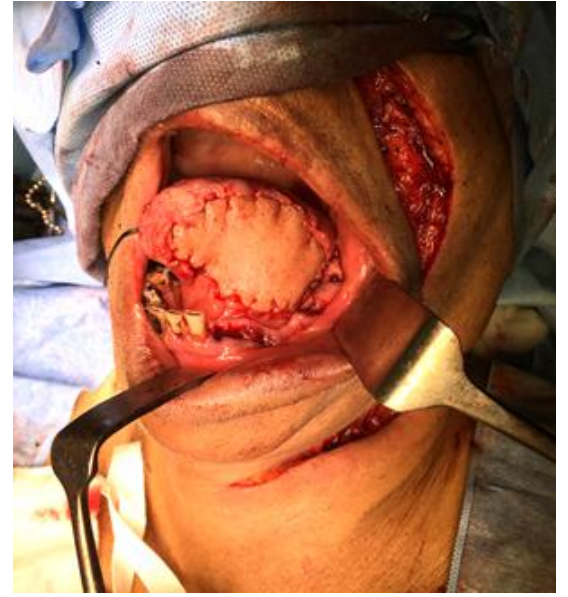

Fig 6: Flap after giving insite to the tongue defect

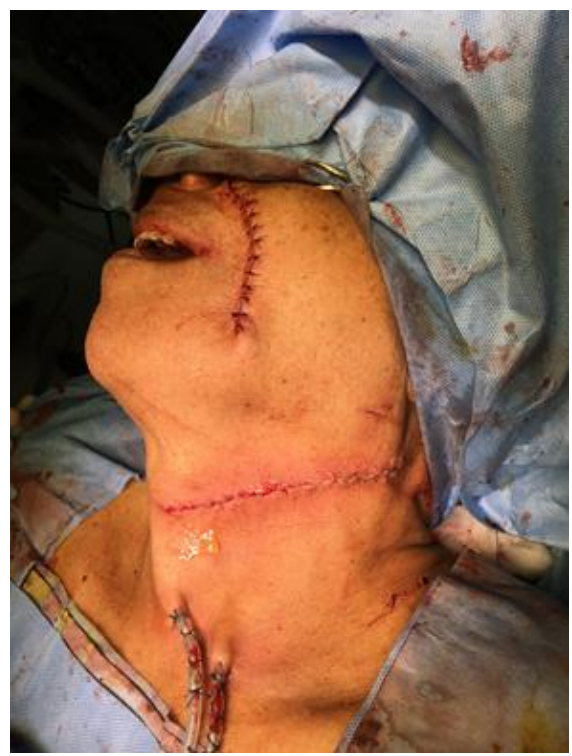

Fig 7: Final appearance post surgery.

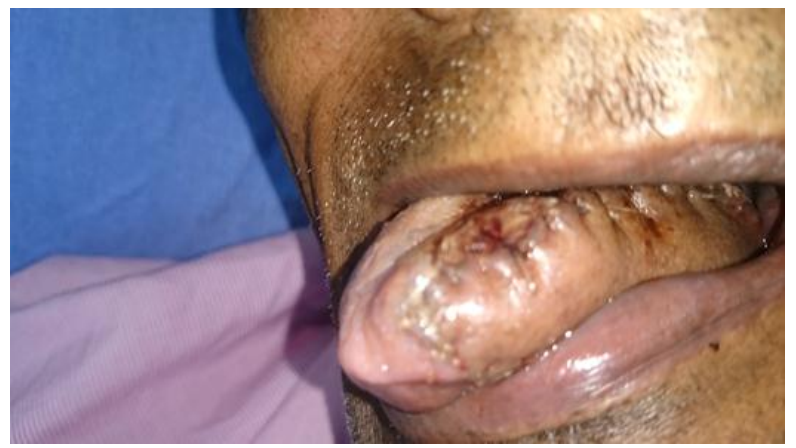

Fig8: ecxcellent tongue movement.

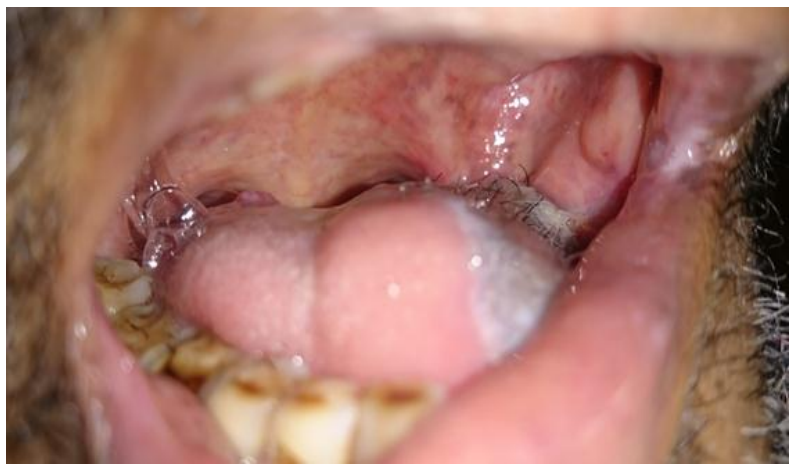

Fig 9: Post op 1month. 
International Journal of Innovative Research in Medical Science (IJIRMS)

Volume 03 Issue 12 Dec 2018, ISSN: 2455-8737, Imp. Factor - 4.102

Available online at $-\underline{w w w . i j i r m s . i n}$

Table 1: Patient Details.

\begin{tabular}{|c|c|c|c|c|}
\hline Case & Age Group & Gender & Comorbidities & Date of Discharge \\
\hline 1 & 65 & $\mathrm{~m}$ & NIL & 3 \\
\hline 2 & 60 & $\mathrm{~m}$ & NIL & 5 \\
\hline 3 & 66 & $\mathrm{~m}$ & Cardiac HTN & 5 \\
\hline 4 & 46 & $\mathrm{~m}$ & Nil & 6 \\
\hline 5 & 40 & $\mathrm{f}$ & ITP, Hypothyroid & 3 \\
\hline 6 & 38 & $\mathrm{~m}$ & NIL & 6 \\
\hline 7 & 54 & $\mathrm{~m}$ & DM,HTN & 4 \\
\hline 8 & 79 & $\mathrm{f}$ & HTN & 4 \\
\hline 9 & 64 & $\mathrm{~m}$ & HTN & 3 \\
\hline
\end{tabular}

M - Male, F - Female, DM -Diabetes Mellitus, HTN - Hypertension, ITP - Idiopathic thromocytopenic purpura

Table 2: Procedure details and outcome

\begin{tabular}{|c|c|c|c|c|c|c|}
\hline Case & $\begin{array}{l}\text { Neoadjuvant } \\
\text { chemotheraphy }\end{array}$ & $\begin{array}{c}\text { Post surgery } \\
\text { Radiotheraphy }\end{array}$ & $\begin{array}{c}\text { Side of flap } \\
\text { harvest }\end{array}$ & $\begin{array}{l}\text { Wide excision defect with respect } \\
\text { to anterior tonsillar pillar(ATP) }\end{array}$ & $\begin{array}{l}\text { Histopathological } \\
\text { size of specimen }\end{array}$ & Flap Failure \\
\hline 1 & $2 \mathrm{PF}$ & 1 & $\mathrm{~L}$ & Till ATP & $5 \times 3.5 \times 1.5$ & Nil \\
\hline 2 & 0 & 1 & $\mathrm{~L}$ & Till ATP & $6.5 \times 4.5 \times 2$ & Tip necrosis \\
\hline 3 & $2 \mathrm{PF}$ & 1 & $\mathrm{~L}$ & $1 \mathrm{~cm}$ infront & $6 \times 5 \times 2.5$ & Nil \\
\hline 4 & 0 & 1 & $\mathrm{~L}$ & Till ATP & $5 \times 4 \times 3$ & Nil \\
\hline 5 & 0 & 0 & $\mathrm{R}$ & Till ATP & $4.5 \times 4 \times 3$ & Nil \\
\hline 6 & 0 & 1 & $\mathrm{R}$ & Till ATP & $5 \times 4.5 \times 3$ & Nil \\
\hline 7 & 0 & 0 & $\mathrm{R}$ & Till ATP & $5 \times 4 \times 3$ & Tip necrosis \\
\hline 8 & 0 & 1 & $\mathrm{R}$ & Till ATP & $5 \times 4 \times 3$ & Full loss \\
\hline 9 & 0 & 1 & $\mathrm{~L}$ & Till ATP & $5.5 \times 4.5 \times 2.5$ & Nil \\
\hline
\end{tabular}

$P F-$ Cisplatin $+5 F U$

\section{Results}

Flap was harvested in all these cases without lip split incision, Neck dissection was performed with a single horizontal cervical crease incision. No tracheostomy was done in any of this patients. Size of the pedicle measure about 9 to $10 \mathrm{~cm}$.

All patients had an uneventful course in the hospital with no complication and were discharged on mean postoperative day 4.3 . Immediate post surgery till discharge no patients had flap loss. 2 patients had flaps which were congested. Complete flap loss was noted in a 79 year old female who was hypertensive and was a chronic panchewer, this was noted on follow up 10th postoperative day, the flap was debrided and defect was left to heal by secondary intention. 2 patients had necrosis in tip of the flap, around $1 \mathrm{~cm}$ which was managed conservatively. Surgery time was less than 200 minutes including tongue resection, neck dissection, flap harvest and reconstruction in all patients. Patient had a good functional outcome. Patients had a good tongue tip, lateral sulcus and mobility were well maintained and all had adequate tongue volume.

Except for the patient with flap failure, functional outcome was good with good tongue mobility in all other patients. Swallowing was adequate. There was no notable deficit word articulation in any of these patients.

\section{Discussion}

The first description of nasolabial flap (NLF) goes back to Susruta in 600BC. Later in 1868 Thiersch explained use of cheek flap to close palatal fistula. In 1918 Esser inferiorly based NLF to close anterior palatal fistula. In 1960 Cramer used NLF to reconstruct floor of mouth defect. In 1976 Elliot explained single stage repair of the defect with inferiorly based NLF and linear closure of donor site. $^{[3,4]}$

Expected incidence of carcinoma tongue is going to have an upsurge from 48,888 in 2015 to 78,991 in $2025 .^{[1]}$ The curative option of tongue lesion is a wide excision of lesion with or without neck dissection followed by radiotherapy when indicated. In an advanced tongue lesion when such an excision is performed speech and swallowing will get affected. This will in turn affect the quality of life of patient. So adequate reconstruction should be performed, for a better quality of life.

Free flaps are ideal for reconstruction of tongue defects, in this modern era. Nasolabial flap is a simple alternative option mainly for anterior tongue based defect, it is highly versatile and a reliable flap. Traditionally use of nasolabial flap has been well documented and excellent functional results are registered. ${ }^{[5]}$

Nasolabial flap can be superiorly or inferiorly based. After tissue harvest, the flap is tunneled into the oral cavity through buccal mucosa. The procedure can be done as a single stage procedure, by burying the pedicle or two stage technique, wherein pedicle is divided in second stage. Proper deepithelialization of tissue is very important failing which leads to development of inclusion cyst or orocutaneous fistula. ${ }^{[6,7]}$ In our institution NLF is widely used for tongue reconstruction, 70 of 224 patient had tongue defect reconstructed by nasolabial flap and this report goes back to 2001 . In this study maximum posterior reach of NLF is $1.5 \mathrm{~cm}$ from anterior tonsillar pillar. ${ }^{[5]}$ In this report flap used was a single staged nasolabial artery island flap based on facial artery and vein and this flap is tunnel under the mandible.

Advantage of nasolabial island flap and tunneling below mandible is mainly excellent tongue mobility (Fig 9) as equivalent to free flap with no additional cost, instrumentation or operation time. 


\section{International Journal of Innovative Research in Medical Science (IJIRMS) \\ Volume 03 Issue 12 Dec 2018, ISSN: 2455-8737, Imp. Factor - 4.102 \\ Available online at $-\underline{w w w . i j i r m s . i n}$}

Another major advantage of this flap is it can reach anywhere inside oral cavity even to the opposite side due to the excellent length of pedicle(Fig 4$),{ }^{[8]}$ this is very important in tongue defect as it gives adequate cover even to posterior $1 / 3$ rd tongue defect. It also gives adequate volume for hemiglossectomy defect. As compared to other conventional NLF, this flap, will not have any problem due to compression of the vascular pedicle, there won't be any complication like inclusion cyst of orocutaneous fistula and it does not require a staged procedure. Speech was intellectual and mobility of tongue was excellent and it doesn't have other postoperative complications of conventional nasolabial flap. Though we don't do tracheostomy in our cases of tongue resection as routine, this flap did not promote any need for tracheostomy. During resection of malignancy oncological principle is to be taken care of, facial artery and facial vein are preserved there is no oncological compromise especially when comparing with submental flap where preglandular area of level $\mathrm{Ib}$ clearance is compromised.

The major disadvantage of flap is related to scar following surgery, but this will become inconspicuous over time. Younger individual might not be willing for this reconstruction. Buccal branch of facial nerve especially which supplies upper lip was sacrificed during procedure, this might have little cosmetic effect on smiling. There will be minimal hair growth in proximal end of the flap (Fig 9), but it is far superior when compared to submental flap. This flap cannot be harvested in cases where large level $\mathrm{Ib}$ node is noted, which can compromise oncological clearance. Deepithelialization of proximal skin might be tried to avoid this hair growth.

Pectoralis major myocutaneous flap is a major workhorse in head and neck reconstruction but this gives a major bulk and segmental mandibulectomy might have to done, this forms a major morbidity. Other locoregional flap or skin graft won't give sufficient volume for tongue and has morbidity of its own. Alternative option would be a submental flap which is not oncologically safe and so it is not preferred. Thus free flap is a preferred option for tongue reconstruction. But the time and expertise required are to be kept in mind. This flap is an effective alternative to free flap, with acceptable cosmesis.

When we balance advantage and disadvantage of this flap, it should be noted this flap should emerge as one of a major flap for reconstruction of defects in oral cavity, needing further large prospective study and further analysis.

\section{Conclusions}

NLFTUM is an excellent option for reconstruction of defects in oral cavity especially tongue with excellent functional outcome. Moreover it can reach any aspect of oral cavity including contralateral side or tongue base. For tongue it provides functional outcome equivalent to free flap and is cost effective.

\section{Reference}

[1] Takiar R, Krishnan SK, Shah VP. A model approach to calculate cancer prevalence from 5 years survival data for selected cancer sites in India-part II. Asian Pac J Cancer Prev APJCP. 2014 Jan 1;15(14):5681-4.

[2] Dupoirieux L, Plane L, Gard C, Penneau M. Anatomical basis and results of the facial artery musculomucosal flap for oral reconstruction. British Journal of Oral and Maxillofacial Surgery. 1999 Feb 1;37(1):25-8.

[3] Napolitano M, Mast BA. The nasolabial flap revisited as an adjunct to floor-of-mouth reconstruction. Annals of Plastic surgery. 2001 Mar 1;46(3):265-8.

[4] Morgan RF, Chambers RG, Jaques DA, Hoopes JE. Nasolabial flap in intraoral reconstruction: review of 55 cases. The American Journal of Surgery. 1981 Oct 1;142(4):448-50.

[5] Varghese BT, Sebastian P, Koshy CM, Thomas S, Cherian T, Ahmed I, Mohan PM. Nasolabial flaps in oral reconstruction: an analysis of 224 cases. British journal of plastic surgery. 2001 Sep 1;54(6):499-503.

[6] Mann R, Srinivasan B, Webb R, Webb A. An unusual complication of nasolabial flap reconstruction. The Annals of The Royal College of Surgeons of England. 2017 Feb;99(2):e60-1.

[7] Lazaridou M, Vaxtsevanos K, Dimitrakopoulos I, Lazaridis N, Antoniades K. Nasolabial pedicled compared with island flaps for intraoral reconstruction of oncological defects: complications, recovery of sensitivity, and assessment of quality of life. British Journal of Oral and Maxillofacial Surgery. 2016 Sep 1;54(7):746-50.

[8] Nueangkhota P, Liang YJ, Zheng GS, Su YX, Yang WF, Liao GQ. Reconstruction of Tongue Defects With the Contralateral Nasolabial Island Flap. Journal of Oral and Maxillofacial Surgery. 2016 Apr 1;74(4):851-9.

\section{Corresponding Author}

\section{Dr. Elizabeth Mathew}

Iype MBBS, DLO, DNB, PhD.

Addition Professor, Department of Head and Neck Surgical Oncology, Regional Cancer Centre, Trivandrum, Kerala

Emailid-elizabethrcc@gmail.com

Institution where the work was done:

Department of head and neck surgical oncology, Regional Cancer Centre, Trivandrum

Short running title: Modified Nasolabial Flap

Source of financial support or funding: Nil.

Financial Disclosure - Nil

Conflict Of Interest - Nil. 